\title{
The Basal Cell Naevus Syndrome Report of a Family with Anosmia and a Case of Hypogonadotrophic Hypopituitarism
}

\author{
D. C. WALLACE,* K. J. MURPHY,† L. KELLY,† and W. H. WARD*
}

Summary. A family with the naevoid basal cell carcinoma syndrome is described. Three affected members in one sibship suffered from anosmia. One member has shown a most severe constellation of defects including cataracts, hypertelorism, and anosmia, together with hypogonadism secondary to partial pituitary dysfunction. It is suggested that this latter also represents a previously unreported manifestation of the syndrome.

There is a small, but important group of genetically determined diseases characterized by a tendency to neoplastic transformation of tissues. Among these is a smaller group in which the expression of the mutant allele would appear to reside in some abnormality of control of tissue differentiation, for they are characterized by the presence of multiple system involvement, hamartomas, and a tendency to malignant transformation. These are the 'phacomatoses'. The condition of hereditary multiple naevoid basal cell carcinoma has certain similarities with this group for it exhibits a quite remarkable constellation of generalized abnormalities of all sorts that are apparently associated with the expression of the mutant allele-basal cell carcinomas, dentigerous cysts, skeletal abnormalities, ectopic foci of calcification, mental abnormality, and many other changes.

The family briefly described here is one of the original kindreds in which the genetic nature of the disorder and the combination of multiple basal cell carcinomas and palmar and solar pitting was recognized (Ward, 1959/1960). Prominence is given to one case (III.7) in this family, because the unusual combination of endocrine and other disturbances represents as far as we are aware, the first description of such anomalies in a person with the naevoid basal cell carcinoma syndrome, and these may prove to represent further manifestations of the basic defect in this condition.

\footnotetext{
Received 8 May, 1972.
* From the Royal Newcastle Hospital, New South Wales, Australia.

t From the Princess Alexandra Hospital, Brisbane, Queensland, Australia.
}

\section{The Family}

The pedigree is given in Fig. 1. The affected individuals undoubtedly have the basal cell naevus syndrome. The manifestation of the disease has varied considerably between members of the family. All the individuals shown as affected have had numerous basal cell carcinomas and porokeratosis of the palms and soles. We have seen and examined III.2, III.4, III.6, III.7, III.8, IV.2, IV.12, IV.13, and have some details from IV.8, IV.10, and IV.11. Among the additional abnormalities noted in these individuals have been excessive stature with span exceeding height (III.6, III.7, and III.8); hypertelorism (III.6, III.7, III.8, and IV.8); early cataracts (II.4, III.6, III.7, and III.8); dentigerous cysts (III.8); abnormal EEG (III.8); and calcification of the falx cerebri and roof of pituitary fossa (III.7 and III.8). All of these are recognized manifestations of the disease (Rook, Wilkinson, and Ebling, 1970). Cases

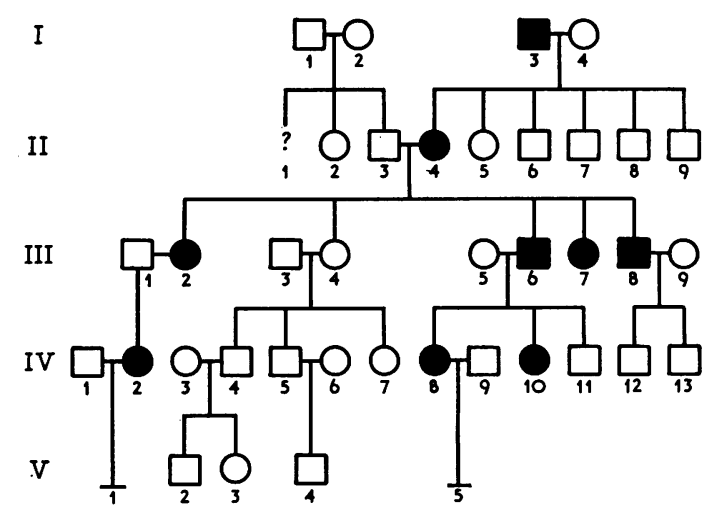

Fig. 1. Pedigree of the family. 
III.2, III.6, III.7, and III.8 had no sense of smell whatsoever, by examination (III.2, III.7 and IV.8) or repute (III.6), while their unaffected sister (III.4) was the only one in their sibship to have normal olfactory ability. Case II.4 has been dead for many years and there is no record of her sense of smell. The members of generation IV have not been adequately examined as the family is now widely dispersed in Australia, New Zealand, and Great Britain.

\section{Case Report}

Case III.7 is the most severely affected in the family.

Clinical Record. The patient first presented at hospital in October 1960, when she was aged 41. She was receiving an invalid pension because of bilateral cataracts. She had had multiple radiotherapy treatments for basal cell carcinomas of the trunk and face since the age of 36 . She had never developed secondary sex characters or body hair and had never menstruated. She had had a normal ${ }^{131}$ I uptake at the age of 37. She did not have polyuria, polydipsia, nor salt craving. She had frequent loose bowel actions, up to four a day. She thought that she could tan if she went in the sun but she avoided sunlight because of her skin cancers. On examination, she was tall and thin, not pigmented, and had no features of Marfan's syndrome. Her height was $176.7 \mathrm{~cm}$ and her span was $180.3 \mathrm{~cm}$. She was wearing size 9 shoes. (She had been wearing size 7 shoes at the age of 21.) There were bilateral dense cataracts but no evidence of lens dislocation. There were multiple radiation scars and several active basal cell carcinomas, but no pitting of palms or soles. There was no body hair and no breast development. The cardiovascular system was normal, including a blood pressure of $140 / 90$ $\mathrm{mm} \mathrm{Hg}$. Chest and abdomen were normal on clinical examination. On rectal examination, a small uterus was palpable, but no other pelvic structures. Tendon reflexes were present but depressed.

Biochemical and Haematological Investigations. The routine full blood count was normal as was the microscopical appearance of the blood smear. Absolute eosinophil counts were 250,250 , and $262 / \mathrm{mm}^{3}$. After intravenous ACTH, the absolute eosinophil count fell to $80 / \mathrm{mm}^{3}$. Serum electrolytes and plasma bicarbonate were normal. Serum cholesterol was $255 \mathrm{mg} / 100 \mathrm{ml}$. The glucose tolerance test showed a flat curve, commencing at $70 \mathrm{mg} / 100 \mathrm{ml}$ and rising to maximum of $95 \mathrm{mg} / 100 \mathrm{ml}$ at 30 minutes falling to $40 \mathrm{mg} / 100 \mathrm{ml}$ at 2 hours.

Radiological Investigations showed generalized loss of bone density. There was slight thoracic scoliosis, the lung fields were clear, and the heart size was normal. None of the ribs showed bifurcation or abnormality of width. The pelvis and lumbar spine also showed diminished bone density and the epiphyseal lines of the iliac crests and the ischial bones were still visible, indicating that the epiphyses were not yet fused. The skull showed a very small pituitary fossa which was bridged over by bone superiorly. The paranasal sinuses appeared greatly increased in size. There was marked calcification of the falx cerebri which was midline in position, and the vault of the skull had a mottled appearance, presumably accentuated by the calcification of the falx. The mandible was small and edentulous and did not contain any cysts. The bones of the hands and feet were less dense than normal and were rather large for a female, but had a normal configuration. There was subcutaneous calcification about several of the proximal phalanges. The distance between the medial canthi was $38 \mathrm{~mm}$, between midpoints of pupils $79 \mathrm{~mm}$, between lateral canthi $108 \mathrm{~mm}$; and on a paranasal sinus film the narrowest distance between the orbits was $\mathbf{5 0}$ $\mathrm{mm}$; this indicated ocular hypertelorism (Hansman, 1966; Walsh and Hoyt, 1969).

Endocrine Function. ${ }^{131}$ I uptake was $19 \%$ at 4 hours and $48 \%$ at 24 hours; this is normal.

On two control days, 24-hour urinary 17 ketosteroids were $3.4 \mathrm{mg}$ and $2.9 \mathrm{mg}$ and 24-hour total 17 hydroxysteroids were $5.8 \mathrm{mg}$ and $5.1 \mathrm{mg}$. After 30 units of intravenous ACTH, the 24-hour urinary 17 ketosteroids rose to $7.8 \mathrm{mg}$ and the 24 -hour 17 hydroxycorticosteroids to $26 \mathrm{mg}$. After $250 \mathrm{mg}$ oral metyrapone given in 12 two-hourly doses the 24-hour 17 ketosteroids were unchanged and the 24-hour 17 hydroxysteroids rose to $10.8 \mathrm{mg}$. These were interpreted to indicate impaired pituitary production of ACTH. The patient was started on $12.5 \mathrm{mg}$ oral cortisone, twice a day, with improvement in her bowel state but no other change in her general condition. The right cataract was removed in November 1960, and the left in August 1963; both were overmature and milky and not diagnostic of any particular cause.

Subsequent tests of pituitary function indicated that protein-bound iodine was $6.7 \mu \mathrm{g} / 100 \mathrm{ml}$, T3 resin uptake was $89 \%$ (normal $85-112 \%$ ), 24-hour urinary gonadotrophins were 0, plasma luteinizing hormone was 0 , and 24-hour urinary oestriol was $70 \mu \mathrm{g}$ (low). A vaginal smear indicated 'extreme atrophy'.

The patient had low fasting levels of growth hormone $(0.7 \mathrm{mg} / \mathrm{ml})$ with a normal reponse to hypoglycaemia (rising to $8 \cdot 1 \mu \mathrm{g} / \mathrm{ml}$ at $45 \mathrm{~min}$ ). The growth hormone level also rose in response to hyperglycaemia. During an insulin tolerance test $(0.15$ units $/ \mathrm{kg}$ body weight) the blood sugar fell below $45 \mathrm{mg} / 100 \mathrm{ml}$ from 30 to $90 \mathrm{~min}$ after the commencement of the test. The plasma cortisol was below the normal range and did not change during hypoglycaemia.

Subsequent Course. After the patient had been receiving the cortisone as above for two years, she was readmitted to hospital because of low back pain. Radiology showed further loss of bone density, plus a compression fracture of the upper surface of the third lumbar vertebra. The epiphyses of the posterior iliac crests and the ischial bones were still unfused. She was given oral calcium lactate and oral dienoestrol, commencing at $0.1 \mathrm{mg}$ twice daily slowly increasing to $0.5 \mathrm{mg}$ daily. The back pain settled with this treatment plus rest in 
bed, but after a month of therapy, the patient refused to take any more dienoestrol, because of the swelling of her breasts and vulva. She declared that it was unfair to produce this result, after 40 odd years without secondary sex characteristics. Thus, her tissues were able to respond to exogenous oestrogens, but the patient disliked the effect produced. During that admission, the serum calcium was $9.6 \mathrm{mg} / 100 \mathrm{ml}$, serum inorganic phosphate $2.7 \mathrm{mg} / 100 \mathrm{ml}$, serum alkaline phosphatase 8.3 KA units $/ 100 \mathrm{ml}$.

The patient has remained stable on oral cortisone and added calcium lactate. The last recording of her height was $172.9 \mathrm{~cm}$, indicating that she may have lost over $3 \mathrm{~cm}$ since commencement of steroid therapy. Her blood pressure has remained of the order of $110 / 80$ to 130/100. The optic discs appear unusually pale but attempts at Bjerrum screen and perimetry were unsuccessful because she was unable to fix without her spectacles, and she had no peripheral vision with the spectacles. The patient's sense of smell was tested with pure oil of cloves and pure oil of peppermint. The patient could not detect either. Both oils were then tested on the tongue, and produced an irritation but no definite sense of taste. The patient's karyotype showed a normal female chromosome count. Her ECG was normal.

This patient shows the syndrome of hypogonadotrophic hypopituitarism with anosmia, showing impaired ACTH production, but normal growth hormone production and normal thyroid stimulating hormone production. She has multiple basal cell carcinomas, hypertelorism, cataracts, calcification of the falx, a mottled appearance of the vault of the skull, and discrete soft tissue calcification about the proximal phalanges of the fingers, which have been noted in association with the basal cell naevus syndrome. She has no cysts in the jaws and bifid ribs, but some degree of thoracic scoliosis.

Hypogonadotrophic hypogonadism with anosmia has been regarded as a sex-linked disorder (Kallman, Shonfeld, and Barrera, 1944) but cases have been noted in females (Tagatz et al, 1970).

\section{Discussion}

In this truly remarkable syndrome many organ systems are involved. The most constant features are the multiple naevoid basal cell carcinomas from which it derives its name, but the palmar and solar dyskeratosis is almost universally present, together with the multiple jaw cysts and skeletal abnormalities.

The presence of anosmia in this family is of interest, as it does not appear to have been described in this syndrome previously, yet the presence of the condition from birth in the three affected sibs in generation III of this family raises strong suspicion of its association with the disease here. One of us (W.H.W.) has noted that, in an unrelated sufferer from the disease, the association appeared at the time of onset of the carcinomas.
It might be questioned whether the endocrine abnormalities in case III.7 are an expression of the mutant gene or represent a chance concurrence of two rare conditions. Until further examples of this clinical picture are recognized in the naevoid basal cell carcinoma syndrome the suggestion that these endocrine disturbances are due to the mutation must remain conjectural unless the basic fault in the disease is uncovered. Yet the other features she demonstrates have all been catalogued. Cataracts (Gorlin and Gotz, 1960), tall and thin appearance (Berlin et al, 1966), hypertelorism (Zackheim, Howell, and Loud, 1966), calcified falx, mottled vault of skull, scoliosis, and soft tissue calcification are recognized aspects of the disease and it may be inferred from the case history that this patient represents a severe example of the disease. There are at least two reports of cases of the naevoid basal cell carcinoma syndrome where the abnormal skeletal development was sufficiently similar to the usual appearance of Marfan's syndrome for this diagnosis to have been suggested (Boyer and Martin, 1958; Davidson 1962). Both of these cases showed gonadal anomalies (infantile genitalia and undescended testes). The present case is tall and thin with big hands and feet but no arachnodactyly, no lens dislocation, no cardiovascular anomaly, and no spina bifida occulta. It is probable therefore that her appearance represents a skeletal response to the hypophyseal abnormality. We consider that this may have been the case in the reports we have cited and perhaps also in her brother (III.6). We feel, therefore, that the balance of probabilities favours a single mutant cause for her troubles, rather than a chance association of two rare conditions.

Despite its protean manifestations, the basal cell naevus syndrome would appear to be commonly a relatively mild disease, permitting those affected to take a normal place in the community, though one of us (K.M.) has observed deep erosion with brain invasion in one case. The defect, therefore, cannot lead to gross interference with developmental or metabolic function. A genetically determined minor inability of cells of ectodermal origin to respond to some normal regulator substance could perhaps lead to these protean manifestations. The formal genetics of the disease have been well detailed by Anderson, McClendon, and Howell (1964), and this family contributes little to genetic understanding of the disease, except to emphasize how variable is the expressivity of the mutation even within the one family, and even between sibs in that family. The basic defect is as far from discovery as ever. 


\section{REFERENCES}

Anderson, D. E., McClendon, J. L., and Howell, J. B. (1964) Genetics and skin tumours with special reference to basal cell nevio. In Tumours of the Skin, 7th Annual Clinical Conference on Cancer, p. 91. Year Book Medical Publishers, Chicago.

Berlin, N. I., Scott, E. J. van, Clendenning, W. E., Archard, H. O., Block, J. B., Witkop, C. J., and Haynes, H. H. (1966). Basal cell nevus syndrome. Annals of Internal Medicine, 64, 403-421.

Boyer, B. E. and Martin, M. M. (1958). Marfan's syndrome: report of a case manifesting a giant bone cyst of the mandible and multiple (110) basal cell carcinomats. Plastic and Reconstructive Surgery, 22, 257-263.

Davidson, F. (1962). Multiple naevoid basal cell carcinomata and associated congenital abnormalities. British fournal of Dermatology, 74, 439-444.

Gorlin, R. J. and Goltz, R. W. (1960). Multiple nevoid basal cell epithelioma, jaw cysts and bifid rib. A new syndrome. New England fournal of Medicine, 262, 908-912.

Hansman, C. F. (1966). Growth of interorbital distance and skull thickness as observed in roentgenographic measurements. Radiology, 86, 87-96.

Kallman, F. H., Schonfeld, W. A., and Barrera, S. E. (1944). Genetic aspects of primary eunuchoidism. American fournal of Mental Deficiency, 48, 203-236.

Rook, A., Wilkinson, D. S., and Ebling, F. J. G. (1970). Textbook of Dermatology, two vols. Blackwell Scientific Publications, Oxford.

Tagatz, G., Fialkow, T. J., Smith, D, and Spadoni, L. (1970). Hypogonadotrophic hypogonadism associated with anosmia in the female. Nerv England fournal of Medicine, 283, 13261329.

Walsh, F. B. and Hoyt, W. F. (1969). Clinical Neuro-Ophthalmology, 3rd ed, vol. 1, p. 686. Williams and Wilkins, Baltimore.

Ward, W. H. (1959/1960). Naevoid basal celled carcinoma associated with dyskeratosis of the palms and soles. A new entity. Australian fournal of Dermatology, 5, 204-208.

Zackheim, H. S., Howell, J. B., and Loud, A. V. (1966). Naevoid basal cell carcinoma syndrome. Archives of Dermatolıgi, 93, 317-323.

The Teratology Society will hold its 13th Annual Meeting from 14-16 June 1973 at Gray Rocks Inn, St. Jovite, Quebec, Canada. The Programme and further information can be obtained from Dr Daphne G. Trasler, Biology Department, McGill University, PO Box 6070, Montreal 101, Canada. 